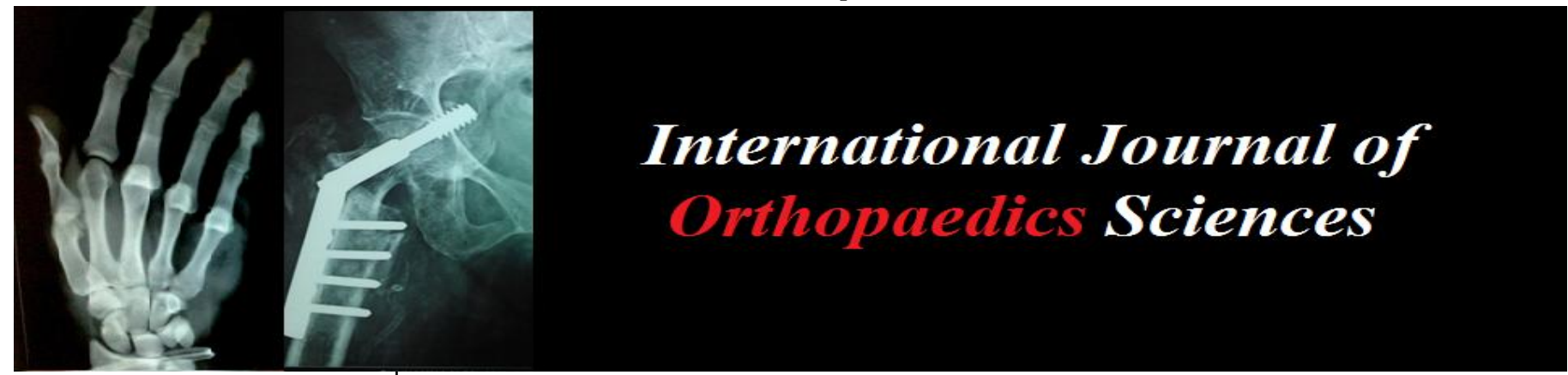

ISSN: $2395-1958$

IJOS 2017; 3(4): 418-421

(C) 2017 IJOS

www.orthopaper.com

Received: 18-05-2017

Accepted: 22-06-2017

Dr. Makesh Ram S

Senior Assistant Professor, Department Of Orthopedics, Government Kilpauk Medical College and Hospital, Chennai, Tamil Nadu, India

Dr. Anand A

Assistant Professor, Department Of Orthopedics, Government Kilpauk Medical College and Hospital, Chennai, Tamil Nadu, India

Dr. Kathir Azhagan S Resident Department of Orthopedics, Government Stanley Medical College and Hospital, Chennai, Tamil Nadu, India
Correspondence Dr. Anand A

Assistant Professor, Department Of Orthopedics, Government Kilpauk Medical College and Hospital, Chennai, Tamil Nadu, India

\section{Comparative functional analysis of intertrochanteric fractures of femur treated with dynamic hip screw with that of proximal femoral nailing}

\author{
Dr. Makesh Ram S, Dr. Anand A and Dr. Kathir Azhagan S
}

DOI: https://doi.org/10.22271/ortho.2017.v3.i4f.58

\begin{abstract}
The intertrochanteric fractures are the most common hip fractures in the elderly in whole world. These factors affect the hip function and stability. A well aligned and stable fixation is the prime goal of treatment of all operative fixation methods. It helps to restore and preserve good hip function following operative fixation. Anatomical restoration of proximal femur, maintenance of mechanical axis and restoration of hip function can be achieved.

Both stable and unstable fractures are fixed now-a-days by various fixation methods. Complex anatomical features, associated complications, patients general condition all have bearing on early surgical management of these fractures.

The study includes 20 patients all of whom were adults. It includes all four types of intertrochanteric fractures < Boyd and Griffin Classification > fixed either with dynamic hip screw fixation and proximal femoral nailing fixation.
\end{abstract}

Keywords: Intertrochanteric fractures, DHS, PFN

\section{Introduction}

Intertrochanteric fractures are caused by road traffic accidents, even low velocity fall injury, especially in elderly patients with osteopenic bone. Treatment of intertrochanteric fracture is by both non-operative and operative methods. Non-operative method includes skeletal traction and derotation boot. Operative methods are by dynamic hip screw, intramedullary nailing and prosthetic replacement.

Two main mode of operative management are dynamic hip screw and intramedullary nailing mainly proximal femoral nailing. Operative treatment has better prognosis and reduces mortality due to fracture. Different types of implants are used according to type of intertrochanteric fracture.

This is a study mainly to analyse the functional outcome of dynamic hip screw and proximal femoral nailing when used in all types of intertrochanteric fractures.

\section{Aim of Study}

Aim is to study the comparative functional outcome of fixation of intertrochanteric fractures with both dynamic hip screw fixation and proximal femoral nailing fixation. All types of intertrochanteric fractures are included in this study to know the outcome.

\section{Materials and Methods}

This is a prospective comparative study of 20 cases of intertrochanteric fractures treated by early surgical fixation with both Dynamic Hip Screw fixation and Proximal Femoral Nailing.

The period of survey and follow up extends from March 2016 to September 2017.

It includes all types of intertrochanteric fractures.

The time protocol extends from within 24 hours of injury to 14 days of injury.

The cases were analysed as per the following criteria.

Age Distribution

Sex Distribution 
Side of Injury

Mode of Injury

Classification of Fractures

Implant Used

Time Interval Between Injury And Surgery

Associated Injuries

Duration Between Injury And Hospitalisation

Duration of Postoperative Stay

Duration of Union - 6 Weeks, 10 Weeks, 14 Weeks

Range of Movements

Postoperative Complications

Rehabilitation

\section{Observations}

This study comprised of 20 patients who were admitted in the Department of Orthopaedics, Government Kilpauk Medical College and Hospital. The following are the observations and the results compiled at the end of study.

Table 1: Age wise distribution $(\mathrm{n}=20)$

\begin{tabular}{|c|c|c|c|}
\hline S. No & $\begin{array}{c}\text { Age Group } \\
\text { (in Years) }\end{array}$ & No. of Cases & Percentage (\%) \\
\hline 1. & $40-50$ Yrs & 2 & 10 \\
\hline 2. & $50-60$ Yrs & 4 & 20 \\
\hline 3. & $60-70$ Yrs & 8 & 40 \\
\hline 4. & $70-80$ Yrs & 6 & 30 \\
\hline
\end{tabular}

Table 2: Sex wise distribution $(\mathrm{n}=20)$

\begin{tabular}{|c|c|c|c|}
\hline S. No. & Sex & No. of Cases & Percentage (\%) \\
\hline 1. & Male & 12 & 60 \\
\hline 2. & Female & 8 & 40 \\
\hline
\end{tabular}

Table 3: Distribution according to mode of injury $(n=20)$

\begin{tabular}{|c|c|c|c|}
\hline S. No. & Type of Injury & No. of Cases & Percentage (\%) \\
\hline 1. & Fall Injury & 12 & 60 \\
\hline 2. & Road Traffic Accidents & 6 & 30 \\
\hline 3. & Fall of Heavy Objects & 2 & 10 \\
\hline
\end{tabular}

Table 4: Distribution according to the side $(\mathrm{n}=20)$

\begin{tabular}{|c|c|c|c|}
\hline Sl. No. & Side & No. of Cases & Percentage (\%) \\
\hline 1. & Left & 12 & 60 \\
\hline 2. & Right & 8 & 40 \\
\hline
\end{tabular}

\section{Classification}

Table 5: Boyd and griffin classification

\begin{tabular}{|c|c|c|}
\hline Type & No. of Cases & Percentage \\
\hline Type - 1 & 6 & $30 \%$ \\
\hline Type - 2 & 8 & $40 \%$ \\
\hline Type - 3 & 4 & $20 \%$ \\
\hline Type - 4 & 2 & $10 \%$ \\
\hline
\end{tabular}

Table 6: Implant used

\begin{tabular}{|c|c|}
\hline Implant Used & No. of Cases \\
\hline Dynamic Hip Screw & 10 \\
\hline Proximal Femoral Nailing & 10 \\
\hline
\end{tabular}

Table 7: Time interval between injury and surgery

\begin{tabular}{|c|c|c|}
\hline Time Interval & No. of Cases & Percentage \\
\hline$<2$ days & 2 & $10 \%$ \\
\hline 2 - 5 days & 10 & $50 \%$ \\
\hline $5-7$ days & 8 & $40 \%$ \\
\hline
\end{tabular}

Associated Injuries

Pubic Ramus Fractures are the most commonly associated fractures with intertrochanteric fractures.

Pubic Ramus Fractures - 3 cases

Shaft of Femur - 1 case

Both Bones Leg fracture - 1 case

Pneumothorax - 1 case

Head Injury - 1 case

Table 8: Operating Time

\begin{tabular}{|c|c|c|}
\hline $\begin{array}{c}\text { Operating } \\
\text { Time }\end{array}$ & $\begin{array}{c}\text { Proximal Femoral } \\
\text { Nailing }\end{array}$ & $\begin{array}{c}\text { Dynamic Hip } \\
\text { Screw }\end{array}$ \\
\hline Type -1 & $1.45 \mathrm{Hrs}$ & $1.30 \mathrm{Hrs}$ \\
\hline Type -2 & $2.10 \mathrm{Hrs}$ & $1.50 \mathrm{Hrs}$ \\
\hline Type -3 & $2.45 \mathrm{Hrs}$ & $2.10 \mathrm{Hrs}$ \\
\hline Type -4 & $2.50 \mathrm{Hrs}$ & $2.20 \mathrm{Hrs}$ \\
\hline
\end{tabular}

Table 9: Blood Loss

\begin{tabular}{|c|c|c|}
\hline Blood Loss & Dynamic Hip Screw & Proximal Femoral Nailing \\
\hline Type -1 & $200 \mathrm{ml}$ & $90 \mathrm{ml}$ \\
\hline Type -2 & $350 \mathrm{ml}$ & $180 \mathrm{ml}$ \\
\hline Type -3 & $400 \mathrm{ml}$ & $220 \mathrm{ml}$ \\
\hline Type -4 & $380 \mathrm{ml}$ & $200 \mathrm{ml}$ \\
\hline
\end{tabular}

Table 10: Unit of blood transfused

\begin{tabular}{|c|c|c|}
\hline $\begin{array}{c}\text { Blood } \\
\text { Transfusion }\end{array}$ & $\begin{array}{c}\text { Dynamic Hip } \\
\text { Screw }\end{array}$ & $\begin{array}{c}\text { Proximal Femoral } \\
\text { Nailing }\end{array}$ \\
\hline Type -1 & 1 Unit & Nil \\
\hline Type -2 & 1 Unit & 1 Unit \\
\hline Type -3 & 2 Units & 1 Unit \\
\hline Type -4 & 2 Units & 1 Unit \\
\hline
\end{tabular}

Table 11: Fluroscopic Exposure

\begin{tabular}{|c|c|c|}
\hline Exposure & Dynamic Hip Screw & Proximal Femoral Nailing \\
\hline Type -1 & $10 \mathrm{~min}$ & $20 \mathrm{~min}$ \\
\hline Type -2 & $15 \mathrm{~min}$ & $25 \mathrm{~min}$ \\
\hline Type -3 & $20 \mathrm{~min}$ & $30 \mathrm{~min}$ \\
\hline Type -4 & $22 \mathrm{~min}$ & $28 \mathrm{~min}$ \\
\hline
\end{tabular}

Table 12: Time of Union

\begin{tabular}{|c|c|c|c|}
\hline Time & 6 Weeks & 10 Weeks & 14 Weeks \\
\hline Dynamic Hip Screw & $28 \%$ & $68 \%$ & $84 \%$ \\
\hline Proximal Femoral Nailing & $36 \%$ & $80 \%$ & $92 \%$ \\
\hline
\end{tabular}

Functional out come

Postoperative follow up

Harris hip score

Pain - max score - 44

Table 13

\begin{tabular}{|c|c|c|}
\hline Months & Dynamic Hip Screw & Proximal Femoral Nailing \\
\hline 3 months & 20 & 30 \\
\hline 6 months & 30 & 40 \\
\hline
\end{tabular}

Table 14: Limp - max score - 11

\begin{tabular}{|c|c|c|}
\hline Months & Dynamic Hip Screw & Proximal Femoral Nailing \\
\hline 3 months & 0 & 5 \\
\hline 6 months & 5 & 8 \\
\hline
\end{tabular}

Table 15: Support - max score 11

\begin{tabular}{|c|c|c|}
\hline Months & Dynamic Hip Screw & Proximal Femoral Nailing \\
\hline 3 months & 3 & 5 \\
\hline 6 months & 5 & 7 \\
\hline
\end{tabular}


Table 16: Distance walked - max score 11

\begin{tabular}{|c|c|c|}
\hline Months & Dynamic Hip Screw & Proximal Femoral Nailing \\
\hline 3 months & 2 & 5 \\
\hline 6 months & 3 & 8 \\
\hline
\end{tabular}

Table 17: Sitting Max Score - 5

\begin{tabular}{|c|c|c|}
\hline Months & Dynamic hip screw & Proximal femoral nailing \\
\hline 3 months & 0 & 3 \\
\hline 6 months & 3 & 5 \\
\hline
\end{tabular}

Table 18: Public transport use - max score 1

\begin{tabular}{|c|c|c|}
\hline Months & Dynamic Hip Screw & Proximal Femoral Nailing \\
\hline 3 months & 0 & 0 \\
\hline 6 months & 1 & 1 \\
\hline
\end{tabular}

Table 19: Stairs max score - 4

\begin{tabular}{|c|c|c|}
\hline Months & Dynamic hip screw & Proximal femoral nailing \\
\hline 3 months & 0 & 1 \\
\hline 6 months & 1 & 2 \\
\hline
\end{tabular}

Table 20: Put on shoes and chappels - max score 4

\begin{tabular}{|c|c|c|}
\hline Months & Dynamic Hip Screw & Proximal Femoral Nailing \\
\hline 3 months & 0 & 2 \\
\hline 6 months & 2 & 4 \\
\hline
\end{tabular}

Table 21: Absence of deformity - max score 4

\begin{tabular}{|c|c|c|}
\hline Months & Dynamic Hip Screw & Proximal Femoral Nailing \\
\hline 3 months & 2 & 3 \\
\hline 6 months & 3 & 3 \\
\hline
\end{tabular}

Table 22: Range of motion - max score 5

\begin{tabular}{|c|c|c|}
\hline Months & Dynamic Hip Screw & Proximal Femoral Nailing \\
\hline 3 months & 2 & 3 \\
\hline 6 months & 3 & 4 \\
\hline
\end{tabular}

Table 23: Total harris hip score

\begin{tabular}{|c|c|c|}
\hline Months & Dynamic Hip Screw & Proximal Femoral Nailing \\
\hline 3 months & 29 & 58 \\
\hline 6 months & 57 & 82 \\
\hline
\end{tabular}

\section{Analysis of functional outcome}

The rating system followed was that of Harris Hip Score which taken into account pain, movement, function, shortening and angulation. This system is easy to follow and analyse. Others systems are more confusing and takes multiple factors for analysis.

Table 24: Overall results

\begin{tabular}{|c|c|c|}
\hline Grading & No. of Cases & Percentage \\
\hline Excellent & 12 & $60 \%$ \\
\hline Good & 3 & $15 \%$ \\
\hline Fair & 3 & $15 \%$ \\
\hline Failure & 2 & $10 \%$ \\
\hline
\end{tabular}

Table 25: Results according to subtype

\begin{tabular}{|c|c|}
\hline Types & Grading \\
\hline Type - 1 & Excellent to Fair \\
\hline Type - 2 & Excellent to Fair \\
\hline Type - 3 & Excellent to Failure \\
\hline Type - 4 & Excellent to Failure \\
\hline
\end{tabular}

Table 26: Results according to the implant used

\begin{tabular}{|c|c|c|c|}
\hline Implant & No. of Cases & Grading & Percentage \\
\hline Dynamic Hip Screw & 6 & Excellent & $60 \%$ \\
\hline & 2 & Good & $20 \%$ \\
\hline & 1 & Fair & $10 \%$ \\
\hline & 1 & Failure & $10 \%$ \\
\hline Proximal Femoral Nail & 7 & Excellent & $70 \%$ \\
\hline & 1 & Good & $10 \%$ \\
\hline & 1 & Fair & $10 \%$ \\
\hline & 1 & Failure & $10 \%$ \\
\hline
\end{tabular}
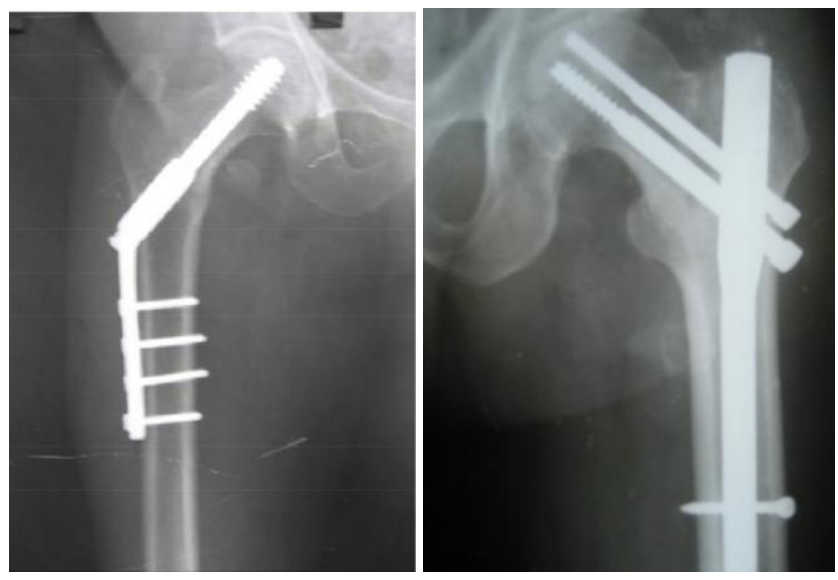

14 Weeks

\section{Discussion}

The aim of study is to evaluate the Comparative functional outcome of the fixation of intertrochanteric fractures with both dynamic hip screw and proximal femoral nailing.

We selected 20 cases of intertrochanteric fractures from March 2016 to September 2017. All 4 types of intertrochanteric fractures are included. We had 6 cases of type- 1,8 cases of type-2, 4 cases of type-3, and 2 cases of type- 4 fractures. Two groups each were fixed with dynamic hip screw and proximal femoral nailing for each groups consisting of 10 cases.

10 cases were fixed with dynamic hip screw and 10 cases were fixed with proximal femoral nailing. The youngest patient in our series is 45 years and oldest patient in our series is 75 years. Average age is 60 years.

We had 12 male cases and 8 female cases. With a ratio of 1.5:1. All the 20 cases were closed fractures. Most common mode of injury is accidental fall injury. In our study, we had 12 cases right sided and 8 cases left sided.

Most common associated injuries are 3 public ramus fractures. Others are 1 shaft of femur, 1 both bones leg fractures, 1 pneumothorax and 1 head injury.

Duration between injury and hospitalization, 10 cases were between 6-12 hrs and 7 cases were more than 12 hours, 2 cases were within 3-6 hrs and 1 case within $3 \mathrm{hrs}$.

All cases were evaluated with $\mathrm{x}$-ray pelvis with both hips anteroposterior view and the affected hip were both anteroposterior and lateral views.

Routine blood investigations with ECG and x-ray chest also taken for assessment for surgery. Traction and internal rotation special view is also taken for the study of the fracture fragments for fixation plan. All 4 types of fractures are fixed with both types of fixation. Preoperative antibiotics are given one hour before surgery.

Dynamic hip screw fixation is by lateral approach with fixation of barrel screw in the femoral head with the side plate 
to the shaft. In Proximal femoral nailing the incision is more smaller just for entry point and screw fixation. 2 cancellous screws, one as lag screw and one as hip pin with distal locking in the shaft. Each step of fixation in both these methods is checked with help of fluoroscopy in both anteroposterior and lateral views.

Operating time is longer for proximal femoral nailing than dynamic hip screw fixation. Type-3 and 4 fractures have longer operative time. Blood loss is more for type-3 and 4 fractures and also for dynamic hip screw fixation. 2 units of blood transfusion done for type- 3 and 4 fractures. Routinely one unit of blood is given for dynamic hip screw fixation. Fluroscopic exposure is more for the proximal femoral nailing than dynamic hip screw.

Duration of postoperative stay is 12 days for dynamic hip screw and 6 days proximal femoral nailing. All postoperative cases were mobilized on first postoperative day itself. Postoperative $\mathrm{x}$-ray is taken and checked for the fixation.

Time of union for dynamic hip screw fixation at 6 weeks is $28 \%, 10$ weeks is $68 \%$ and 14 weeks is $84 \%$. Time of union for proximal femoral nailing at 6 weeks is $36 \%$, 10 weeks $80 \%$ and 14 weeks is $92 \%$. Full weight bearing allowed only after evidence of full radiological union.

Postoperative outcome of both fixation is measured by Harris Hip Score. Pain is mild in proximal femoral nailing compared to dynamic hip screw nailing. Limping is less in proximal femoral nailing. Assisted distance walked, using public transport, absence of deformity, sitting, using stairs, range of motion are better in proximal femoral nailing in both 3 and 6 months of follow up using Harris hip score than dynamic hip screw.

Functional outcome is excellent in 12 cases, good in 3 cases, fair in 3 cases and failure in 2 cases. Type- 1 and 2 fractures have excellent to fair results. Type- 3 and 4 fractures have excellent to failure results. Dynamic hip screw has $60 \%$ excellent results, whereas proximal femoral nailing has $70 \%$ excellent results.

In our study, Postoperative complications noted was infection in 4 cases, malunion in 2 cases, delayed union in 2 cases, bed sores in 1 patient, limb length inequality in 5 patients, none of them had any functional deficit, but there was lag screw pull out in one case.

No vascular and neurological complications were noted in these 20 cases.

In our study, outcome of fixation is studied extensively from operation table till full union function till 6 months of follow up.

\section{Conclusion}

In our study, on assessing the functional outcome of intertrochanteric fractures, we reached the following conclusions.

1. Intertrochanteric fractures commonly occur in men around age of $6^{\text {th }}$ decade due to accidental fall injury.

2. Conventional radiographs are not essential to study the fracture pattern, traction and internal rotation view is needed to classify the fractures.

3. Boyd and Griffin classification is essential for classification of intertrochanteric fractures.

4. Fracture stabilization by rigid internal fixation by both methods results in early functional recovery and early ambulation. Perfect anatomical reduction gives excellent results.

5. Blood loss and unit of blood transfusion is less in case of proximal femoral nailing compared with dynamic hip screw.

6. Operative time is longer in proximal femoral nailing than dynamic hip screw.

7. Fluroscopic exposure is longer for proximal femoral nailing than dynamic hip screw.

8. Duration of postoperative stay is longer in dynamic hip screw than proximal femoral nailing.

9. Results of both fixation are better in type-1 and 2 fractures compared with type- 3 and 4 fractures.

10. Union rates are also better in type- 1 and 2 fractures with both fixation than type- 3 and 4 fractures.

11. Postoperative follow up was measured by Harris Hip Score for a follow up of 3 and 6 months.

12. Pain, limp, support, distance walked, sitting, public transport, walking stairs, put chapels, absence of deformity. All these factors are better in proximal femoral nailing for 3 and 6 months follow up than dynamic hip screw.

In our series, proximal femoral nailing has better results than dynamic hip screws. Proximal femoral nailing has better union rates and functional results than dynamic hip screw. It has very good results even in type- 1 and 2 stable fractures. Intraoperative and postoperative complications are less in proximal femoral nailing. But the disadvantage is screw pullout, <z-effect> is seen and also the operative time and fluoroscopic time is longer which is hazardous to the patient.

\section{References}

1. Albareda J, Laderiga A Pavanead et al. Int ortho op. 1996; 20:47-50.

2. Baungaetner Mi, Crostowski Jh, Levy $\mathrm{Rn}$ Inter Trochanteric Hip Bromer $\mathrm{Bd}$ eds. Skeletal trainna Philadelphia. Wb Sasunders. JBJS 1995-1992-18331881; 2(2 Articles).

3. Bella Barba. C Nerslovici. Jn D RICCI WM Percutaneous treatment of peri trochanteric Clinical ortho. 2000; 375:34.

4. Boyd, Hb Griffin Ll, Classification - Treatment of Trochanteric Arch surg, 1949.

5. Bride Sn, Pastel AD Bircher M. CCalvert PT. Fixation of intertrochanteric of Tnefemur. A randomnised prospective companison of the 'r' nail \& the dynamic hip screw. Journal of Bone Joint Surgery, 1991.

6. Calvert PT ' $\mathrm{r}$ ' nail A significant advance or as passing failure? JBTs - 1992.

7. Ceeng CL, Punwk et al., long term results complications of treatment.

8. Augmentation in the treatment of unstable trochanteric injury

9. Cunnings SR. WEVITT. MC Non skeletal determinants of the potential importance of the mechanic of fall Osteoporosis int, 1994, suppl 1.

10. Davis TR SnER JL. Hersman A et al., intertrochanteric femoral Mechanical failure after Int' fixation. JBJs, 1990.

11. Dimon JN hugnston JC unstable intertrochanteric of hip JBJs 1967 clinical orthop, 1973, 92. 